\title{
Preservation of Fetal Brain Blood Flow Relative to Other Organs during Hypovolemic Hypotension
}

\author{
W. A. TWEED, ${ }^{(20)}$ JACQUES COTE, JOHN G. WADE, GEORGE GREGORY, AND ALEX MILLS \\ Department of Anesthesia, University of Manitoba, Winnipeg, Manitoba, Canada
}

\section{Summary}

The asphyxiated newborn is particularly vulnerable to hypotension, which contributes to hypoxic brain damage by reducing cerebral perfusion. During asphyxia, cerebral blood flow (CBF) is pressure passive, that is, $\mathrm{CBF}$ autoregulation is abolished. It is important to know if the nonasphyxiated fetus and newborn are similarly vulnerable to hypotension. In the present study, we have measured acute responses of organ blood flow to a hypovolemic/ hypotensive stress in the normoxic near term sheep fetus. Changes in brain flow were compared to changes in other organs.

Eight chronically prepared fetal lambs were studied. Organ blood flows were measured by the microsphere technique during a control period, after a $20 \%$ blood volume reduction, and again after reinfusion of that volume.

Hypovolemia was accompanied by a $21 \%$ decrease in blood pressure and a 4 torr increase in Pco2; after reinfusion blood pressure increased $16 \%$ above control. Control measurements of organ perfusion were similar to those reported by other investigators. Cardiac output and flow to all organs, with the exception of the brain, were reduced $30-56 \%$ during hypovolemia. Brain blood flow was insignificantly reduced by $9 \%$. If a correction is applied for the increase in $\mathrm{Pco}_{2}, \mathrm{CBF}$ corrected to control $\mathrm{Pco}_{2}$ would have been significantly reduced by $18 \%$. After reinfusion, flow to all organs increased to near control levels.

We conclude that the normoxic fetal lamb shows evidence of $\mathrm{CBF}$ autoregulation, and is able to preserve relative constancy of $\mathrm{CBF}$ within a blood pressure range of $\pm 20 \%$ of normal. However, the evidence presented in this study suggests that autoregulation may be less effective in response to a hypotensive stress, even though CBF is better preserved than flow to most other organs.

\section{Speculation}

The brain of the lamb is more mature than that of the human at birth. Although the normoxic fetal lamb shows evidence of cerebral blood flow autoregulation, these studies suggest that even under normal physiologic conditions in utero, the fetal brain may not be fully protected against acute hypotension. This may be because the normal fetal blood pressure is close to the lower limit of autoregulation. Previous work by ourselves and others has also demonstrated the vulnerability of autoregulation to hypercapnea, hypoxia, and acidosis. Since these are common manifestations of fetal and newborn asphyxia, and even to some extent of the normal birth process, it is reasonable to speculate that autoregulation is generally impaired when there is fetal or newborn distress. Therefore, cerebral blood flow of even the nonasphyxiated neonate may be vulnerable to marked deviations of blood pressure.

As the fetus approaches term, a high cardiac output is the most important adaptive mechanism maintaining oxygen delivery to fetal organs in the low oxygen tension of the in utero environment. Recent investigations (4) suggest that the term sheep fetus may be approaching its maximum circulatory capacity. However, this maximum may be determined by uterine environmental condi- tions, possibly including myocardial oxygen supply, since a further 2 to 3 times increase in left ventricular output occurs in the newborn lamb in response to increased oxygen consumption after birth (8). Thus, although Gilbert (4) found no increase in biventricular cardiac output with increased preload in the fetal lamb, Klopfenstein and Rudolph (8) observed a 35\% increase in left ventricular output during preloading at 1 wk of age. Fetal lambs do not respond to an hypoxic stress with increased cardiac output, but redistribute a fixed or reduced output to maintain oxygen delivery to vital organs (1). This requires well developed cardiovascular regulatory mechanisms which are triggered by hypoxia (3). The term fetus appears to be in a peculiarly vulnerable circulatory state. Having virtually achieved its maximum in utero cardiac output, it must respond to stress primarily by redistribution of flow. Local regulation of organ blood flow is therefore a major factor in the adaptive circulatory response to fetal stress. Thus, it is particularly important to know if the brain differs from other organs in the regulation of its flow in both normal and stress states.

It is well recognized that, when hypoxia or asphyxia threaten oxygen delivery, the brain is the most vulnerable organ. The asphyxiated newborn is, in addition, particularly vulnerable to hypotension, which contributes to hypoxic brain damage by reducing cerebral perfusion (11). Current understanding of cerebral blood flow $(\mathrm{CBF})$ regulation suggests that this occurs because asphyxia renders the CBF pressure passive, i.e., impairs cerebrovascular autoregulation (12). It is not known if the nonasphyxiated newborn or fetus is similarly vulnerable to hypotension. Since hypotension is commonly observed in the newborn (14), this is a question of great practical significance.

The studies here reported were done to measure acute responses of organ blood flow to a hypovolemic/hypotensive stress in the normoxic near term sheep fetus. The response of brain flood flow to changing blood pressure was of particular interest.

\section{MATERIALS AND METHODS}

We studied eight near-term fetal lambs estimated to be 130 140 days gestation. Surgical preparation was done under halothane/oxygen general anesthesia with controlled ventilation via an endotracheal tube. The ewe was placed in the supine position and femoral arterial and venous catheters inserted. Through a midline abdominal approach, a small hysterotomy was made to expose the fetal limbs. A hind limb was delivered and femoral arterial and venous catheters (0.86 mm ID, $1.27 \mathrm{~mm} \mathrm{OD)} \mathrm{were}$ advanced to the descending aorta and inferior vena cava. A forelimb was then delivered and a similar axillary artery catheter advanced to the common brachio-cephalic trunk. The incisions were closed and all catheters were brought subcutaneously to a pocket on the ewe's flank. Prophylactic antibiotics were administered to both mother and fetus daily until the studies were complete (penicillin G 1000,000 IU to the ewe, 500,000 IU to the fetus; gentamycin $60 \mathrm{mg}$ to the ewe, $30 \mathrm{mg}$ to the fetus).

Studies were performed 30-72 hr after surgical preparation. In the laboratory, the ewe stood quietly in a cart and was allowed 
hay and water ad libitum. Fetal and maternal arterial blood pressures and fetal venous pressures were continuously recorded with Statham P23 pressure transducers and an H.P. dynograph. Maternal femoral and fetal ascending aortic blood gases were measured with a Corning 165 blood gas analyzer, and percent hemoglobin saturation measured with a microoximeter (Radiometer OSM-2 Hemoximeter) (10). Oxygen contents were measured by a micromanometric method (9). Maternal rectal temperature was monitored.

Fetal organ blood flows were measured by the microsphere technique, using $15 \mu \mathrm{m}$ diameter microspheres labelled with gamma emitting $\mathrm{Ce}^{141}, \mathrm{Cr}^{51}$, or $\mathrm{Sr}^{85}$ (3M Company). For each measurement, approximately 1 million spheres were injected into the inferior vena cava over $30 \mathrm{sec}$. Arterial blood samples were withdrawn at a fixed rate, $1.94 \mathrm{ml} / \mathrm{min}$, from the brachiocephalic and descending aortic catheters, during and for $1.5 \mathrm{~min}$ after microsphere injection. Radio-nuclide levels in the blood samples and ashed tissue samples were counted in a Searle $\gamma$ well counter.

After the ewe had rested quietly in the laboratory for l-2 hr, a complete set of control measurements were made. Fetal hypotension was then produced by withdrawal of fetal arterial blood. Sixty to $150 \mathrm{ml}$ of blood (average 92.8 ) were withdrawn over 5-10 min to reduce mean arterial blood pressure (MABP) by approximately $20 \%$. After 5-15 min, blood pressure had stabilized under hypotensive conditions and a complete second set of measurements were made. The heparinized blood was then reinfused and within $15 \mathrm{~min}$ a third set of measurements were made.

At the end of this experiment mother and fetus were painlessly killed with intravenous sodium pentothal and saturated $\mathrm{KCl}$ solution. The fetus was autopsied to validate catheter placement, then fetal organs were weighed and ashed for radionuclide counting.

If microspheres are homogenously distributed in the arterial blood supplying an organ, and are completely removed from blood during passage through the organ, then the following equation (6) calculates organ blood flow:

$$
\mathrm{F}=\frac{\mathrm{Fa} \times \mathrm{i} \text { organ }}{\mathrm{i} \text { arterial }}
$$

where $F=$ organ blood flow $(\mathrm{ml} / 100 \mathrm{~g} / \mathrm{min}) ; \mathrm{Fa}=$ withdrawal rate of the reference arterial blood sample; i organ $=$ microsphere content of the organ tissue $(\mathrm{cpm} / 100 \mathrm{~g}) ; \mathrm{i}$ arterial $=$ microsphere content of the total reference arterial blood sample (cpm). All comparisons were made using the paired $t$ test with each fetus serving as its own control.

\section{RESULTS}

The results are presented from studies in eight animals of gestational age 130-140 days and average weight $3.04 \mathrm{~kg}$, excluding placenta. Measurements during hypovolemic hypotension were obtained in eight animals and after re-infusion in five animals.

Table 1 lists the average results of physiologic measurements in the control state and after fetal hypovolemia and re-infusion. The hypovolemic data consist of eight pairs of measurements, the reinfusion data of 5 pairs. If feto-placental blood volume is estimated to be $135 \mathrm{ml} / \mathrm{kg}$ (2), then an average of $20 \%$ of blood volume was removed, resulting in a $21 \%$ reduction in MABP. After reinfusion MABP overshot control by $+16 \%$. Venous pressure changes were similar in direction and magnitude to those described by Gilbert (4). The increase in heart rate with hypovolemia was insignificant and no changes occurred in $\mathrm{PO}_{2}$, oxygen saturation, or $\mathrm{O}_{2}$ content. A small but significant increase in $\mathrm{PCO}_{2}$ was observed during hypovolemia (39.3 to 43.5 torr) and a corresponding decrease in $\mathrm{pH}$. A decrease in fetal hemoglobin and hematocrit during hypovolemia indicates a small but significant hemodilution.

Absolute fetal organ blood flows in $\mathrm{ml} / \mathrm{g} / \mathrm{min}$ during the control state are illustrated in Table 2 . Lung is not included because we did not have a reference sample of pulmonary arterial blood.
Liver flow is at the limit of accurate measurement because microspheres in the hepatic-venous circulation are trapped in the gut and only the small hepatic arterial perfusion reaches the liver. Biventricular cardiac output (C.O.) was estimated by addition of total organ flows, but underestimates true cardiac output by an amount equal to pulmonary artery flow, normally $4-5 \%$ of total C.O. (17). The control measurements are very similar to other results reported in the literature $(1,4,17)$.

Figure 1 illustrates organ flow and C.O. during hypovolemia and reinfusion, as percent of control. The reduction in C.O. and all organ flows during hypotension, with the exception of brain, are striking and significant. Brain flow was insignificantly reduced by $9 \%$ while the reduction in perfusion to other tissues was $30-$ $56 \%$. After reinfusion, there was a variable increase in flow to all organs, but only myocardial flow was significantly increased above control.

Percent distribution of cardiac output to fetal organs during volume changes is illustrated in Figure 2. Some active redistribution of biventricular C.O. during hypovolemia is evident, with a statistically significant increase in the proportion going to the brain and a nonsignificant increase to placenta. The proportionate distribution to the gastrointestional tract and carcass was significantly reduced, evidence for active vasoconstriction in these organs.

\section{DISCUSSION}

The fetal lamb close to term is unable to increase its cardiac output when stressed by hypoxemia and/or acidemia. In a model similar to ours, Cohn et al. (1) demonstrated that fetal C.O. fell by $25 \%$ during a moderate hypoxemia/acidemia stress $\left(\mathrm{PO}_{2}=12, \mathrm{pH}\right.$ $=7.28$ ), but the decrease in flow was not proportional in all organs. Perfusion of the heart, brain, and adrenals increased, while all other fetal organs and the carcass suffered a decrease. Evidently, very powerful regulatory mechanisms are stimulated under those circumstances, resulting in a striking redistribution of a reduced total C.O. The strength of these responses is even more evident when one considers that the placenta, a low resistance circuit in which the flow is practically pressure passive, accepts about half the C.O. Those studies demonstrate clearly that, when threatened by hypoxemia/acidemia, the sheep fetus mobilizes a powerful vasonconstrictor response, probably mediated by the sympathoadrenal system (3), which redistributes C.O. and protects the vulnerable brain. Peeters et al. (15) have nicely demonstrated that this response is triggered when the fetal ascending aortic $\mathrm{O}_{2}$ content reaches the 2-3 millimolar range, and before acidosis supervenes.

Brain blood flow increases up to $500 \%$ in some regions during hypoxia or asphyxia if systemic arterial blood pressure (BP) is maintained $(7,15)$. These observations are consistent with our understanding of cerebrovascular physiology in these circumstances. Hypoxia causes cerebral vasodilatation and impairs cerebrovascular autoregulation to $\mathrm{BP}$ changes, that is, $\mathrm{CBF}$ is rendered pressure passive. As long as systemic vasoconstrictor responses are active and maintain normal or elevated BP, cerebral hyperemia will be expected (12).

When our present studies are examined with those of Gilbert (4), we conclude that compensatory vasoconstrictor responses are activated by a $20 \%$, but not by a $10 \%$ reduction in blood volume and MABP. Thus Gilbert (4) observed a relatively small decrease in flow to most organs, including the brain, after reduction of fetal blood volume by $10 \%$; but the distribution of C.O. remained fairly constant. Our observations suggest an active redistribution of C.O., with a significant increase in the proportion going to the brain, and a decrease to the gut and carcass (Fig. 2). In other organs, e.g., kidneys and skin, perfusion appeared to vary directly with cardiac output. The baroreflex is certainly intact and baroreflex modification of heart rate is easily demonstrated in the fetus $(13,18)$. However, in comparison to the studies of Cohn et al. (1) and Peeters et al. (15), it appears that a $20 \%$ reduction in BV, though causing the same reduction in C.O., is not as potent a stimulus in eliciting reflex vasoconstriction and redistribution of 
Table 1. Baseline fetal and maternal measurements during fetal blood volume changes (mean \pm S.D.)

\begin{tabular}{|c|c|c|c|c|c|}
\hline Variable & \multicolumn{4}{|c|}{ Fetal } & $\begin{array}{c}\text { Maternal } \\
\text { Control (8) }\end{array}$ \\
\hline MABP torr & $52.4 \pm 2.7$ & $41.3^{1} \pm 3.4$ & $49.3 \pm 3.8$ & $57.2^{2} \pm 5.2$ & $94.8 \pm 2.3$ \\
\hline Mean venous pressure torr & $10.9 \pm 2.6$ & $10.1 \pm 2.8$ & $8.8 \pm 1.5$ & $9.9 \pm 1.1$ & \\
\hline Heart rate & $174 \pm 7$ & $190 \pm 12$ & $176 \pm 7$ & $170 \pm 8$ & $101 \pm 6$ \\
\hline $\mathrm{pH}$ & $7.407 \pm 0.010$ & $7.378^{1} \pm 0.012$ & $7.412 \pm 0.012$ & $7.389 \pm 0.018$ & $7.507 \pm 0.010$ \\
\hline $\mathrm{O}_{2}$ sat. $(\%)$ & $53.7 \pm 6.6$ & $59.6 \pm 7.9$ & $58.2 \pm 6.1$ & $57.3 \pm 7.5$ & \\
\hline $\mathrm{O}_{2}$ Cont. (vol. \%) & $7.1 \pm 0.1$ & $6.9 \pm 0.1$ & $7.2 \pm 0.1$ & $6.8 \pm 0.1$ & \\
\hline Hemoglobin $(\mathrm{g} / 100 \mathrm{ml})$ & $11.5 \pm 1.1$ & $10.2 \pm 0.7$ & $11.5 \pm 1.1$ & $11.3 \pm 1.0$ & \\
\hline Hematocrit $(\%)$ & $28.2 \pm 1.2$ & $25.5^{2} \pm 1.6$ & $28.2 \pm 1.2$ & $26.2^{2} \pm 1.4$ & \\
\hline
\end{tabular}

Fetal and maternal physiologic status during control state and fetal blood volume changes. Hypovolemic data includes eight pairs of measurements, reinfusion data five pairs. Comparisons are by paired $t$ test.

${ }^{1} P<0.01$ compared to control.

${ }^{2} P<0.05$ compared to control.

Table 2. Control fetal organ flow rates $(\mathrm{ml} / \mathrm{g} / \mathrm{mm})$

\begin{tabular}{lcl}
\hline \multicolumn{1}{c}{ Organ } & Mean & S.D. \\
\hline Brain & 1.17 & 0.15 \\
Heart & 1.69 & 0.20 \\
Kidney & 1.85 & 0.20 \\
Liver & 0.05 & 0.01 \\
Spleen & 4.32 & 0.77 \\
Stomach & 0.44 & 0.07 \\
Small bowel & 1.47 & 0.10 \\
Large bowel & 0.87 & 0.12 \\
Carcass & 0.22 & 0.03 \\
Skin & 0.18 & 0.03 \\
Placenta & 0.85 & 0.09 \\
Cardiac output & 0.375 & 0.04 \\
\hline
\end{tabular}

Biventricular cardiac output was estimated by summation of the values for total organ flow and is presented as $\mathrm{ml} / \mathrm{g}$ total fetoplacental weight.

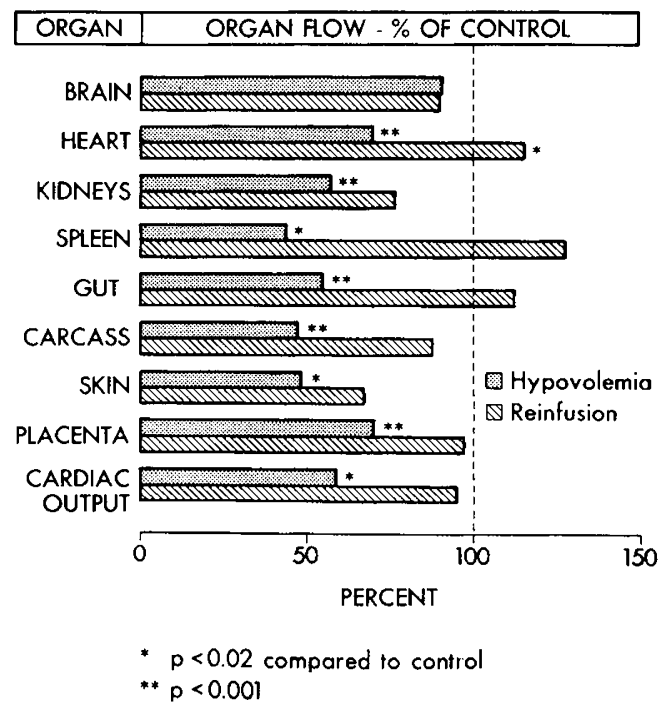

Fig. 1. Fetal organ flow rates during hypovolemia and reinfusion as percent of control. Comparison was by paired $t$-test. Each bar represents a mean value. ${ }^{*} P<0.02$ compared to control; ${ }^{* *} P<0.001$ compared to control.

C.O. as are mild hypoxemia or acidemia. This suggests that the carotid and aortic chemoreceptors, not the baroreceptors, are the principle reflex sensors in fetal cardio vascular regulation. In arriving at this conclusion we are ignoring the small changes in

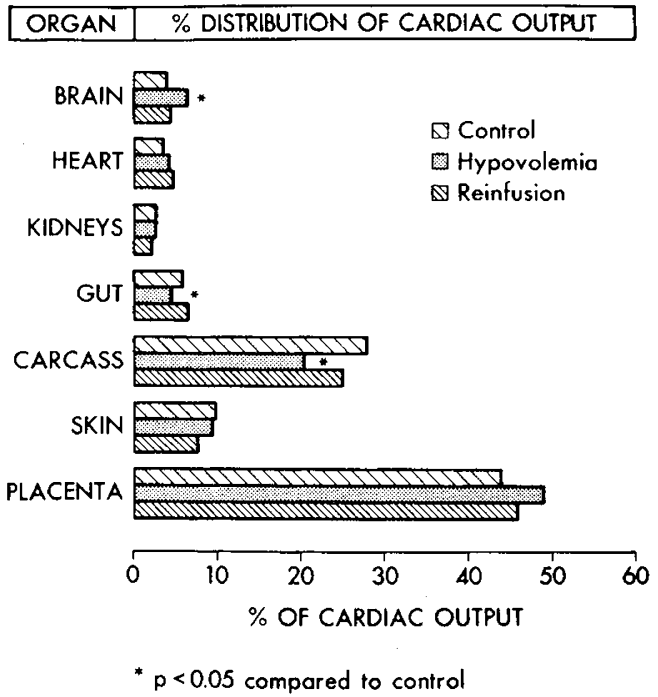

Fig. 2. Percentages of the cardiac output distributed to individual fetal organs following volume changes. Each bar depicts the mean of five values. ${ }^{*} P<0.05$ compared to control.

$\mathrm{PCO}_{2}$ and $\mathrm{pH}$ in our study which were well within the physiologic range.

The apparent difference in response of brain blood flow to hypotension observed by Gilbert (4) and ourselves is explicable. We believe that our studies provide evidence for autoregulation of $\mathrm{CBF}$ in the fetal lamb when subjected to acute blood pressure changes, if ideal physiologic conditions prevail, i.e., $\mathrm{PCO}_{2}$ approximately $40, \mathrm{pH}$ about 7.40 , and $\mathrm{O}_{2}$ saturation over $50 \%$. The difference between Gilbert's animals and ours is in $\mathrm{PCO}_{2}$ and $\mathrm{pH}$, his with an average $\mathrm{PCO}_{2}$ of near 50 and $\mathrm{pH}$ of 7.33. The vasodilating effects of $\mathrm{PCO}_{2}$ above 45 torr are well known and present also in young animals (16). This is confirmed by the high control CBF in Gilbert's report (4), $181 \mathrm{ml} / 100 \mathrm{~g} / \mathrm{min}$, higher than other reports of control $\mathrm{CBF}$ in similar animal models $(1,7,17)$. Impairment of autoregulation by hypercapnea is also well known (5), particularly in the lower range of blood pressure. It is therefore quite reasonable to conclude that Gilbert's animals showed a pressure passive CBF response to decreasing $\mathrm{BP}$ because of impaired autoregulation secondary to mild hypercapnea. In autoregulation studies of Haggendal and Johansson (5) in adult dogs, autoregulation was abolished at an arterial $\mathrm{O}_{2}$ saturation below $60 \%$ and a $\mathrm{PCO}_{2}$ above 50 torr, but appeared to be restored at lower levels of $\mathrm{PCO}_{2}$. Therefore, available evidence indicates that in the restricted $\mathrm{O}_{2}$ environment in utero, autoregulation of $\mathrm{CBF}$ 


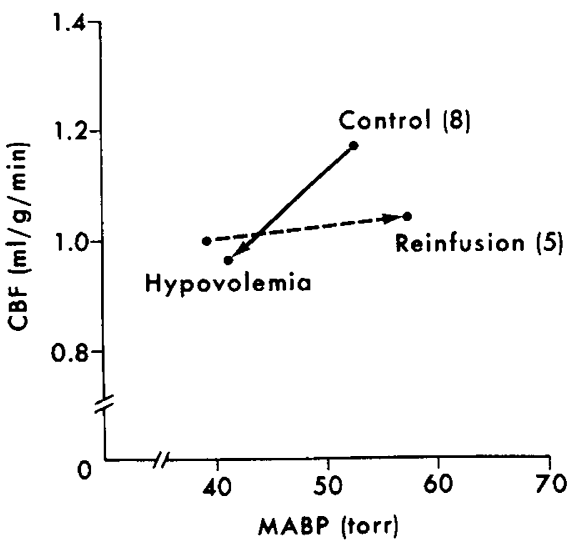

Fig. 3. Fetal $\mathrm{CBF}$ corrected to control $\mathrm{PCO}_{2}$ at different blood pressures. The solid line illustrates the mean values for eight pairs of measurements for decreasing MABP i.e., control to hypovolemia. The decrease in $\mathrm{CBF}$ is significant at the $P<0.05$ level by paired $t$-test. The dashed line illustrates the mean values for five pairs of measurements for increasing MABP, i.e., hypovolemia to reinfusion. The increase is not statistically significant.

is tenuous, and probably only demonstrable at lower $\mathrm{PCO}_{2}$ tensions and optimal $\mathrm{O}_{2}$ saturation.

For example, in 1969 Purves and James (16) reported autoregulation of $C B F$ in the fetal and newborn lamb. Although they studied acutely exteriorized fetal lambs, arterial blood gases were normal (mean $\mathrm{Po}_{2} 23-24$, mean $\mathrm{PCO}_{2} 40$ ). They found that gray matter blood flow was independent of MABP over the range 4390 torr (fetuses) and 45-93 torr (newborn lambs). Although they also reported no disturbance of the autoregulation curve in three fetuses after modest $\mathrm{PCO}_{2}$ elevation, this observation is difficult to interpret because they did not report the initial $\mathrm{PCO}_{2}$ values.

However, $\mathrm{PCO}_{2}$ effects as a partial explanation for out observations of apparent CBF constancy must be considered. There was a small but consistent rise of $\mathrm{PCO}_{2}$ during hypovolemia, averaging 4 torr, probably due to reduced fetal placental perfusion. This change in $\mathrm{PCO}_{2}$ should increase CBF by $2.4 \mathrm{ml} / 100 \mathrm{~g} / \mathrm{min} / 1$ torr $\mathrm{PCO}_{2}$, according to the results of Purves and James (16), and would counteract the decrease in flow occurring if autoregulation was impaired. That would still not account for the total difference between the brain and other organs, i.e., correcting CBF in hypovolemia to control $\mathrm{PCO}_{2}$ results in only a calculated $18 \%$ decrease $(P<0.05)$ (Fig. 3), compared to $30-56 \%$ in other organs. After reinfusion, $\mathrm{PCO}_{2}$ corrected $\mathrm{CBF}$ increased less than $5 \%$ (NS), despite an 18 torr increase MABP.

Therefore we conclude that, under ideal physiologic circumstances, the mature fetal lamb shows evidence of autoregulation of $\mathrm{CBF}$ to $\mathrm{BP}$ changes in the range of $\pm 20 \%$. However, hypotension in utero is accompanied by a rise in fetal $\mathrm{PCO}_{2}$, probably as a result of decreased fetal placental perfusion. If fetal CBF during hypotension is corrected for the rise in $\mathrm{PCO}_{2}$, and compared to control CBF, it appears that autoregulation in response to hypotension may be incomplete. Thus, although the fetal brain preserves constancy of its flow better than most organs, CBF in the nonasphyxiated perinate may still be vulnerable to marked deviations in blood pressure, particularly in the hypotensive direction.

\section{REFERENCES AND NOTES}

1. Cohn, H. E., Sacks, J. E., Heymann, M. A., and Rudolph, A. M.: Cardiovascular responses to hypoxemia and acidemia in fetal lambs. Am. J. Obstet. Gynecol. 120: 817 (1979).

2. Creasy, R. K., Drost, M., Green, M. W., and Morris, J. A.: Determination of fetal, placental, and neonatal blood volumes in the sheep. Circ. Res., 27: 487 (1970).

3. Dawes, G. S., Lewis, B. V., Milligan, J. F., Roach, M. R., and Talner, N. S Vasomotor responses in the hind limbs of fetal and newborn lambs to asphyxia and aortic chemoreceptor stimulation. J. Physiol., 195: 55 (1968).

4. Gilbert, R. D.: Control of fetal cardiac output during changes in blood volume. Am. J. Physiol., 238: H80 (1980).

5. Haggendal, E., and Johansson, B.: Effects of arterial carbon dioxide tension and oxygen saturation on cerebral blood flow autoregulation in dogs. Acta Physiol. Scand., 66 (Suppl 258): 27 (1965).

6. Hales, J. R. S.: Radioactive microsphere techniques for studies of the circulation. Clin. Exp. Pharmacol. Physiol., I (Suppl) (1974).

7. Johnson, G. N., Palahniuk, R. J., Tweed, W. A., Jones, M. V., and Wade, J. G.: Regional cerebral blood flow changes during severe fetal asphyxia produced by slow umbilical cord compression. Am. J. Obstet. Gynecol., 135: 58 (1979).

8. Klopfenstein, H.S., and Rudolph, H. M.: Postnatal changes in the circulation and responses to volume loading in sheep. Circ. Res., 42: 839 (1978).

9. Kirk, B. W., and Raber, M. B.: A practical apparatus for rapid determination of blood oxygen content. J. Appl. Physiol., 34: 724 (1973).

10. Lister, G., Walter, T. K., Versmold, H. T., Dallman, P. R. and Rudolph, A. M.: Oxygen delivery in lambs: cardiovascular and hematologic development. Am. J. Physiol., 237: H668 (1979)

11. Lou, H. C., Lassen, N. A., and Friis-Hansen, B.: Low cerebral blood flow in hypotensive perinatal distress. Acta Neurol. Scand., 56: 342 (1979).

12. Lou, H. C., Lassen, N. A., Tweed, W. A., Johnson, G., Jones, M., and Palahniuk, R. J.: Pressure passive cerebral blood flow and breakdown of the blood brain barrier in experimental fetal asphyxia. Acta Paediatr. Scand., 68: 57 (1979).

13. Maloney, J. E. J., Cannata, M. H., Dowling, W., Maloney, J. E., Cannata, J., Dowling, M. H., Else, W., and Ritchie, B.: Baroreflex activity in conscious fetal and newborn lambs. Biol. Neonat., 31: 340 (1977).

14. Modanlou, H., Yeh, S. Y., Siassi, B., and Hon, E. H.: Direct monitoring of arterial blood pressure in depressed and normal newborn infants during the first hour of life. J. Pediatr. 84: 553 (1974).

15. Peeters, L. I. H., Sheldon, R. E., Jones, M. D., Jr., Makowski, E. I., and Meschia, G.: Blood flow to fetal organs as a function of arterial oxygen content. Am. J. Obstet. Gynecol., 135: 637 (1979).

16. Purves, M. J., and James, I. M.: Observations on the control of cerebral blood flow in the sheep fetus and newborn lamb. Circ. Res., 25: 651 (1969).

17. Rudolph, A. M., and Heymann, M. A.: The circulation of the fetus in utero: methods for studying distribution of blood flow, cardiac output, and organ blood flow. Circ. Res., 21: 163 (1967).

18. Shinebourne, E. A., Vapaavuori, E. K., Williams, R. L., Heymann, M. A., and Rudolph, A. M.: Development of baroreflex activity in unanesthetized fetal and neonatal lambs. Circ. Res., 31: 710 (1972).

19. The authors wish to acknowledge with thanks the financial support of the Medical Research Council of Canada and the Manitoba Heart Foundation, and the technical help of Mr. Wayne Pucci and Miss Maureen Cumming. We also wish especially to recognize the valuable discussions we have had with Hans C. Lou and Neils A. Lassen at the formative stage of this work.

20. Requests for reprints should be addressed to: W. A. Tweed, M.D., Department of Anesthesia Health Sciences Centre-General, 700 William Avenue, Winnipeg, Manitoba, Canada R3E OZ3.

21. Received for publication November 18,1980

22. Accepted for publication April 23, 1981. 